Original research article

\title{
A methodology for the identification of strategic technological competences: An application in the sheet metal equipment industry
}

\author{
Cláudio Santos $^{\mathrm{a}, *}$, Madalena Araújo ${ }^{\mathrm{a}}$, Nuno Correia ${ }^{\mathrm{b}}$ \\ a Department of Production and Systems, University of Minho, Campus de Azurém, 4800-058 Guimarães, Portugal \\ ${ }^{\mathrm{b}}$ Institute of Mechanical Engineering and Industrial Management (INEGI), Rua Dr. Roberto Frias 400, $4200-465$ Porto, Portugal
}

\section{A R T I C L E I N F O}

\section{Keywords:}

Delphi method

Quality function deployment

Foresight

Strategic technological competency

Sheet metal equipment

\begin{abstract}
A B S T R A C T
This paper proposes a technology foresight methodology based on the development of a complementary approach to the Delphi method that enables the identification of strategic technological competences, and presents its application in a sheet metal processing equipment manufacturer. The proposed methodology takes into consideration synergies between future events through a modified QFD matrix, and the application involved a panel of experts from industry and academia. The proposed methodology can benefit organizations by promoting a homogeneous perspective on existing relationships between external drivers and technology diffusion. This study contributes for the understanding of the links between foresight and technology strategy formulation. Further implementations in industrial environments should be performed to refine the methodology and increase the confidence level on the expected results that these findings can signify.
\end{abstract}

\section{Introduction}

Increasingly shorter innovation cycles observed in a number of industries comes with greater challenges to organizations. With varying degrees of importance across industrial sectors, analysing the process by which technologies are diffused has been assuming a central role in the strategy formulation process (Burgelman, Christensen, \& Wheelwright, 2001; Chiesa, 2001; Kameoka, Yokoo, \& Kuwahara, 2004). Decisions such as which technologies to invest in, their mode of acquisition and how to develop new and/ or leverage internal technological competences are made in a context of great complexity and uncertainty.

The analysis of technology diffusion in an industrial sector should consider externalities related with the changes in markets, economies and other factors, which can influence the diffusion process (Linton, 2002). Therefore, a holistic perspective incorporating possible relationships and synergies between these factors is required to develop scenarios that reflect the future impact of technologies.

The objective of this paper is twofold: 1) to develop a technology foresight methodology that complements the results from the Delphi method through the analysis of the relationships between different future events, with the ultimate goal of supporting the identification of strategic technologies and competences and 2) to present the findings derived from an application of the methodology in a technology foresight study conducted in a European mid-sized manufacturer of sheet metal processing machinery.

With the support of the team of researchers, industry and academia experts were interviewed and a panel of experts was then surveyed. The survey's results were used as inputs to an events' relationship analysis to support both the impact assessment of external drivers in the diffusion of technologies, and the development of the technology strategy of the manufacturer.

\footnotetext{
* Corresponding author.

E-mail addresses: claudio.santos@dps.uminho.pt (C. Santos), mmaraujo@dps.uminho.pt (M. Araújo), ncorreia@inegi.up.pt (N. Correia).
} 
This article is structured as follows: Section 2 presents the literature review and a contextualization of the case where this study was conducted with emphasis put on the drivers of technological change. Section 3 describes the research design of this study. Section 4 describes the proposed methodology, from the preparation and results of the Delphi survey to the development and application of the methodology. Section 5 presents the conclusions.

\section{Literature review}

This section presents the literature with respect to technology foresight method and tools, with a special emphasis on the emerging paradigm and the Delphi method. The last sub section presents an overview of the drivers of technological change in the industry under study.

\subsection{Technology foresight}

\subsubsection{Concept}

The term "technology foresight" is typically associated to exercises that involve research and development of strategic innovation plans taking into consideration long-term future technological advancements (Miles, 2010). Such exercises can take place at various levels (organizational, regional, national and supranational) and acknowledge the complexity and dynamism of technology evolution, thus addressing a broader perspective that explores synergies with other domains of knowledge (Pietrobelli \& Puppato, 2016). As a matter of fact, the perspective on technology foresight has evolved from the conventional process or linear approach towards a systemic view (Dufva \& Ahlqvist, 2015).

The scope of technology foresight studies typically addresses macro-environment issues (the "non-market drivers of change") namely Political, Economic and Regulatory changes; micro-environment topics such as emerging needs of customers and industrial sectors (the "market drivers of change") and technology, more specifically, which technologies will have the greatest impact, their likely diffusion rates, drivers and barriers for diffusion, likely substitute technologies and the state of the art in technological variables for the future (Vecchiato \& Roveda, 2010).

\subsubsection{Technology foresight in organizations}

Technology foresight has emerged, particularly for innovation-oriented organizations, as a process for the renewal of strategic resources and value creation (Rohrbeck \& Schwarz, 2013; Rohrbeck, 2012) and for managing environmental uncertainty (Vecchiato, 2015). The practice of foresight for the definition of public policies for science and technology at the national level is well documented (Chakravarti, Vasanta, Krishnan, \& Dubash, 1998; Chang, Wang, Yuan, \& Chuang, 2002; Czaplicka-Kolarz, Stańczyk, \& Kapusta, 2009; de Figueiredo Porto, Marques, \& Santos, 2010; Shin, 1998) and evidence suggests that such studies have been gradually shifting towards the incorporation of broader perspectives beyond the sole technology domain, i.e., including future societal and economy challenges (Meissner, 2012). However, few studies are disclosed at the corporate level, mostly due to confidential reasons.

Literature indicates that there are many challenges in embedding foresight activities in corporations. In corporations with mature practices and a dedicated foresight group, the incorporation of such activities into innovation and strategy processes over time demonstrated complementarity with other business functions (e.g. marketing, product strategy, etc.), diversity and flexibility of topic agendas (Ruff, 2015). Foresight's inherent nature to defy norms and basic assumptions about innovation triggers cultural resistance (Rohrbeck \& Gemünden, 2011) that can bring considerable challenges for the practice of foresight in organizations. These challenges could in turn be addressed by an organizational futurist (Hines \& Gold, 2015), an internal facilitator who would be responsible for the integration of foresight activities inside an organization. The human element is critical in this regard: despite the contributions brought by the advancements witnessed in ICT (Heiko, Bañuls, Turoff, Skulimowski, \& Gordon, 2015; Raford, 2015; Rohrbeck, Thom, \& Arnold, 2015) and in social media (Kayser \& Bierwisch, 2015), foresight practice implies creativity and insight and, for these reasons, remains as an activity centred in humans (Keller \& Heiko, 2014).

In companies, technology foresight can be a one-time activity or a continuous process, which can be performed by a single business, a group or even a whole industry (Carlson, 2004). Depending on the size of the business, technology foresight can also have different types of value (Coates et al., 2001). In large organizations, innovation is increasingly dependent on networks of collaboration; which demand internal capabilities for absorption of external information, in the way that technology foresight can be used as input for the formulation of technology strategies. However, in small companies with resources limitations, there may be strong restrictions to investing in technology foresight. However, with the growing strategic role that technological innovation is having in many industrial sectors, smaller companies are forced to become more technologically informed. According to Coates et al. (2001) and Phaal et al. (2006), there is a great need nowadays for the development of easily comprehensible, integrated, robust, practical and cheap technology foresight methods for smaller businesses.

\subsubsection{Trends in technology foresight tools}

From an evolutionary perspective, foresight studies have also experienced a number of paradigms shifts (Heiko, Vennemann, \& Darkow, 2010). These shifts have had a direct influence on the development of tools and methods. The emerging paradigm "Open foresight" (Miemis, Smart, \& Brigis, 2012) acknowledges that the future cannot be accurately predicted. Thereby, Open Foresight puts more emphasis on open communication, creativity, discussion of contradictory information, ambiguity and provides a structured basis for action-making, recognizing the dynamic interactions of social, technological and economic 
dimensions. Under this paradigm, methods and tools used are characterized by their transparency, hybridity, context orientation and open participation of relevant stakeholders.

A considerable number of tools have been proposed under the domain of technology foresight to support the analysis of the future state of technology (Georghiou et al., 2008; Porter, 2010), and the development of foresight methods should consider inevitably the institutional context (van Meulen \& der Lohnberg, 2001). These technology foresight tools have been object of analysis by researchers, which proposed a number of classifications to support their applicability in different contexts. Mishra, Deshmukh, and Vrat, 2002 proposed a classification based on the approach followed by the tools: subjective assessment methods are based on the subjective evaluations and opinions of experts in particular field(s), and typical examples of such methods are formal surveys, experts' elicitation, focus groups and others. The exploratory methods present extrapolations of existing technological capabilities and include methods such as scenario building, the Delphi method, cross impact analysis, technology substitution models, morphological research, trend extrapolations, growth models etc. The normative approaches identify desirables outcomes based on future technological needs, such as Operations Research models, simulations, relevance trees, system dynamics and others. Rohrbeck et al. (2007) emphasize the perspectives addressed by the tools, and classify them into three classes: market-oriented, technology-oriented and integrating methods, i.e., capable of coping with multiple perspectives. The combination of tools is another trend observed in technology foresight research (Chan \& Daim, 2012; Haegeman, Marinelli, Scapolo, Ricci, \& Sokolov, 2013; Phaal, Farrukh, \& Probert, 2006; Stelzer, Meyer-Brötz, Schiebel, \& Brecht, 2015). The development of hybrid and combined methodologies has been pointed out as critical to increase the effectiveness of the forecasts (Anderson, Daim, \& Kim, 2008; Reger, 2001; Wang \& Lan, 2007), to integrate perspectives (Heger \& Rohrbeck, 2012) and thus ensure that objective, interpretative and personal types of knowledge are considered (Maio Mackay \& Metcalfe, 2002).

\subsection{The Delphi method}

The Delphi method is one of the most known tools in technology foresight. The Delphi method is a structured communication process where a group of individuals attempt to consensually solve a complex problem (Linstone \& Turoff, 2002). The method is based on the premise that group judgements provide more effective solutions than individual judgements. Recent applications of the Delphi method have been increasing, mostly driven by the growing interest in technology foresight and by the advances in information and communication technologies (ICT), which facilitate computer-assisted asynchronous communication and enable users to participate in any stage of the decision-making process (Linstone \& Turoff, 2011).

The foundations of the method rely on four principles (Rowe, Wright, \& Bolger, 1991): anonymity of participants; iterations through a number of rounds; controlled feedback, where participants are able to comment and critique on the judgements of others made so far; and statistical group response, where descriptive statistics of the quantitative judgements are provided to participants after each round. In this sense, the features of the Delphi method fit with the open foresight paradigm, since the method is "one of the best known methods for dealing with open-ended and creative aspects of a problem because it motivates independent thought" and get groups to gradually form solutions (Gupta \& Clarke, 1996).

In line with the trend towards combinations between technology foresight tools, the Delphi method has been often combined with other foresight methods, for either enhancing their analytical capability or contributing as input to others (Rowe \& Wright, 2011). Examples include combinations with Scenario Analysis (Kameoka et al., 2004; Nowack, Endrikat, \& Guenther, 2011), Technological Substitution Models (Tseng, Cheng, \& Peng, 2009), Cross Impact Analysis (CIA) (Bañuls \& Turoff, 2011), Prediction Markets (Prokesch, von der Gracht, \& Wohlenberg, 2015) and the Analytic Hierarchy Process (Meesapawong, Rezgui, \& Li, 2014).

Despite its potentialities, the method has a number of inherent deficiencies. In the Delphi method, events are assessed in isolation, i.e., without the consideration of their synergies, and experts may provide views that are logically inconsistent (Gordon \& Pease, 2006). In technology foresight, since the unit of analysis is technology, it would be desirable to analyse how events in other fronts, namely in market, regulations, politics and others might influence the diffusion of technologies. The issue concerning the lack of mechanisms to account for inter-relationships between events has already been identified as a limitation of the Delphi method (Bañuls \& Turoff, 2011; Gordon \& Pease, 2006).

Another drawback of the Delphi method is related to the absence of strategic guidance or of an explicit link with technology strategy. The Open Foresight paradigm points to greater integration of divergent perspectives, which should be directed towards the definition of a strategy (Heiko et al., 2010). Although different methods incorporate multiple perspectives and consider the definition of a strategy as their ultimate goal, an explicit link between foresight and strategy development is still not fully observed in current foresight methods.

The Delphi method is frequently used as a tool to identify major technological trends in the initial stages of technology strategy development (Eto, 2003; Johnston, 2001; Phaal, Farrukh, \& Probert, 2004; Wonglimpiyarat, 2007). The typical content of a technology strategy program includes the definition of the technologies that are going to be incorporated in the design of future products and/or services, the acquisition mode of such technologies, the necessary technological competences and capabilities and the timing of introduction of the technologies (Burgelman et al., 2001; Chiesa, 2001). The selection of the technologies can be performed by analysing the events related to the technologies with the greatest impact as identified by experts in the Delphi method. The timing of introduction is analysed within the response to Delphi survey questions such as when, in the expert's opinion, the events portrayed in the survey are most likely to occur. The decision concerning the required technological competences and capabilities is dependent on the technologies selected and existing competences and capabilities within the organization (the "competence gap"). This analysis can determine actions such as hiring new engineers, purchasing specific equipment, establishing partnerships with organizations with complementary competences or others. The decision concerning how to acquire the technology (i.e. develop in-house, in partnership 
or purchase a license) also requires detailed information from patents, scientific publications, and other sources for the identification of potential technology suppliers.

Considering the aforementioned deficiencies of the Delphi method and in consonance with the emerging foresight paradigm and the propositions supporting robust, economic and practical foresight tools, this paper presents the development and application of a technology foresight methodology that complements the Delphi method by enabling the cross-analysis of future events. The same methodology has been applied in a foresight study conducted with a manufacturer of sheet metal processing equipment.

\subsection{Technological change: drivers and frameworks}

\subsubsection{Drivers of technological change}

The process of technological change in industrial equipment sectors is shaped by a range of systemic factors or drivers (Carlsson \& Jacobsson, 1994; Kong, 1996). In the specific case of the machine tool industry, the case under analysis in this study, evidence suggests that this process has been influenced by a set of events over the last decades. This section presents a perspective on this industry, highlighting the role of future external drivers, as well as the frameworks that have been proposed to improve the understanding about their effect on the process of technological change in the industry.

The impact that technology brings to the competitiveness of machine tool manufacturers is well illustrated by the changes brought by the integration of digital controls and computers into machine tools (Arnold, 2001). A major event contributed to the widespread integration of numerical controls in machine tools: the oil crisis and subsequent energy crisis deeply affected the largest industrialized nations of the world. Machine tool users started to search for ways to increase the efficiency of their operations, and numerical control in machine tools offered improved flexibility, by increasing the number and the range of geometric shapes that could be produced, and reduced operating costs, through increased automation. Demand for such machines in the US and Western Europe, which were experiencing higher labour costs, rose dramatically.

Relevant to mention is that the development of this technology was greatly supported, during the 1960s and 1970s, by national programs promoted by some industrialized countries, primarily, Japan and Germany, a policy that was not followed at the same scale in the US.

These historical facts illustrate the influence of certain external factors in the diffusion of a technology. This industry, characterized as having long re-investment cycles, was forced to seek more efficient solutions due to the turbulence caused by events (energy crisis, labour issues, national programs) outside of their sphere of influence. Despite this, one cannot ignore the disruptive nature of the technology, which brought higher productivity gains.

The machine tool industry is nowadays seen as having a strategic role in the competitiveness of nations (Commission, 2012) given its importance to the development of new goods and services and to the modernization of industrial processes. Boosted by R \& D programs, it is expected that, in the coming years, new technological developments will considerably change the landscape of this industry.

The machine tool industry is now faced with new challenges. The Comité Européen De Coopération Des Industries De La MachineOutil (CECIMO) ${ }^{1}$ regularly publishes special reports that contain important insights about the current and future status of the global machine tool industry. The report "Study on the Competitiveness of the European Machine Tool Industry" (CECIMO, 2011) addresses how the grand societal challenges, namely globalization of the economy, climate change, scarcity of resources, ageing of society and sustainable mobility, will influence future technological developments of the machine tool industry.

The challenges of economic globalization, characterized by an increasing importance of emerging markets (Gardner, 2014) have led to developments directed towards more efficient management of operations overseas, such as remote access technologies for monitoring operations and equipment, and tele-service technologies to support customers based in different parts of the World. Demand volatility experienced at a global level is also driving the development of flexible manufacturing systems (FMS), including the modularization of equipment and their integration into production systems.

Environmental concerns are stimulating the implementation of more stringent safety regulations, energy-efficiency standards and market surveillance of non-compliant capital goods (CECIMO, 2012). Initiatives such as the Blue Competence Machine Tool (CECIMO, 2013) and the EcoDesign directive (Commission, 2009) aim at increasing awareness about sustainable practices early on the design phases of machine tool equipment. Additionally, the trend towards lightweight constructions are imposing technical challenges for machine tool manufacturers, driving the development of high precision technologies, such as net or near net shape processing technologies, additive manufacturing technologies and novel materials fabrication, including composites, aluminium and high strength steel.

Finally, the decrease in birth rates and the ageing of society, particularly noted in developed countries, brings problems of workforce shortage and skills gap. To respond to this challenge, machine tool manufacturers are investing in automation, simulation and tool-patch verification and rendering, and also in improvements in machine-user interface, such as vision systems for "smart" machines, i.e., machines with self-monitoring and repairing capabilities.

\subsubsection{Frameworks}

In order to improve the understanding about the aforementioned systemic factors, frameworks have been proposed to characterize the influence of drivers and the role of actors and entities in the technologies' diffusion process. The framework proposed by Kathuria (1999) characterizes the influence of external drivers in inducing technological change in the machine tool industry. It portrays four actors, whose interactions basically define the environment of machine tools producers: suppliers, users/customers, State

\footnotetext{
${ }^{1}$ CECIMO is the European Association of the Machine Tool Industries, which is constituted by national associations of 15 European countries that together account to $99 \%$ of the total machine production in Europe and $30 \%$ worldwide.
} 
and competitors. Interactions between these actors determine the rate of technological change in the industry. Such interactions occur in three forms: pressures, incentives and information flow.

An additional actor was identified by Ariss, Raghunathan, and Kunnathar, 2000: the regulatory bodies or agencies. These agencies, which can be national or supranational, pass regulations and set standards that many times influence the directions of technological developments. An example is the numerous new regulations that favour the diffusion of "green" technologies, derived from a growing concern with the environment.

Based on these ideas presented above, the framework proposed by Santos (2014) attempts to describe the role of external determinants in promoting the diffusion of technologies. In this framework (see Appendix A), external determinants are defined as all the non-technology related determinants that induce technological change in the machine tool industry. This perspective expands Kathuria's proposition, by including external drivers at a higher level, such as drivers from Politics, Economics, Environment and Social contexts. This division resembles the STEEP analysis, without the Technology element.

The interactions between actors and drivers take course through a process that begins with the identification of future challenges, the analysis of these challenges, decision and action making, and the monitoring of their effect. These actions are responses through the development of new technological solutions to mitigate the effect of current problems or to anticipate a future problem. Interactions between actors and drivers reflect pressures and incentives for the development of technologies to respond to emerging needs. Thus, in the framework proposed by Santos (2014), technological change is a function of the interactions between drivers and actors. Such interactions have been mentioned throughout this section, and point to the need for a holistic perspective on the development and application of technology foresight methodologies.

\section{Research design}

This study follows the principles of case study research method described by Yin (2009). Case study is an appropriate research method because this is a study focused on sets of contemporary events, over which the researcher has few or no control, but is interested in their direct observation. According to Yin, there are three types of case studies: explanatory or causal, descriptive and exploratory. This paper presents a descriptive case study since it is intended to provide a detailed report of a case from which relevant knowledge is extracted through its analysis. In addition, this study is not intended to build causal links between events or concepts such as in an explanatory case study - and is based on existing knowledge, namely about technology foresight tools, so it cannot be classified as exploratory case study.

In designing case studies research, there are five components that are particularly relevant: the study's questions, the unit of analysis, the propositions and the logic and criteria for interpreting the results (Yin, 2009).

The study's research questions are driven by the research motivation and by a review of relevant literature to identify potential gaps; they will also provide relevant insights for the choice of the research approach and methods. As mentioned earlier, the study aims to understand how the deficiencies of the Delphi method can be addressed, as described in the literature review.

The unit of analysis is the identification of the case to be studied. This study is conducted in the sheet metal processing equipment industry, which is a key segment in the machine tool industry, since more than a half of the world production of metal is destined to sheet metal parts (Streppel, Klingenberg, \& Singh, 2008). More specifically, in this study the unit of analysis is a single company: a European medium sized manufacturer of equipment for sheet metal processing. The company's top management recognizes the importance to continuously invest in the technologies that will have a considerable impact in the sheet metal processing equipment industry in the future.

The study's proposition is aligned with the branch of the literature that posits that, by combining foresight techniques, the deficiencies of stand-alone techniques (such as the Delphi method) can be overcome. In this study, a new methodology that uses the inputs from the Delphi method is proposed to address such deficiencies. Data is collected through the application of the methodology in the company, and the observation of such application provided inputs for interpreting the results and deriving the findings of the study.

The application involved two phases: one related to the preparation and application of the Delphi method, and the second related to the application of the proposed methodology which have as inputs the survey' results from the Delphi method. Each phase includes a number of stages, which are illustrated in Fig. 1 and described below.

\subsection{Definition of the key technological domains}

an analysis on the systems and subsystems in sheet metal processing technologies was carried out, with support of the Chief Technology Officer (CTO) and engineers from the technical department of the company. The sheet metal industry is a multi-technological industry, therefore, this analysis was necessary to support the identification of the necessary technological backgrounds of the experts that were going to be interviewed for this study.

Nine technological domains were identified: Information and Communication Technologies (ICT), Materials, Robotics, Automation, Optics and Photonics, Sensing, Mechatronics, Machine Design and Industrial Electronics.

\subsection{Review on selected publications}

A review on selected publications was performed to identify major technological trends

Online scientific databases were used in this research. In order to filter the most relevant publications, keywords such as "trends"; "new developments"; "progress"; "forming" and "sheet metal" were used. 


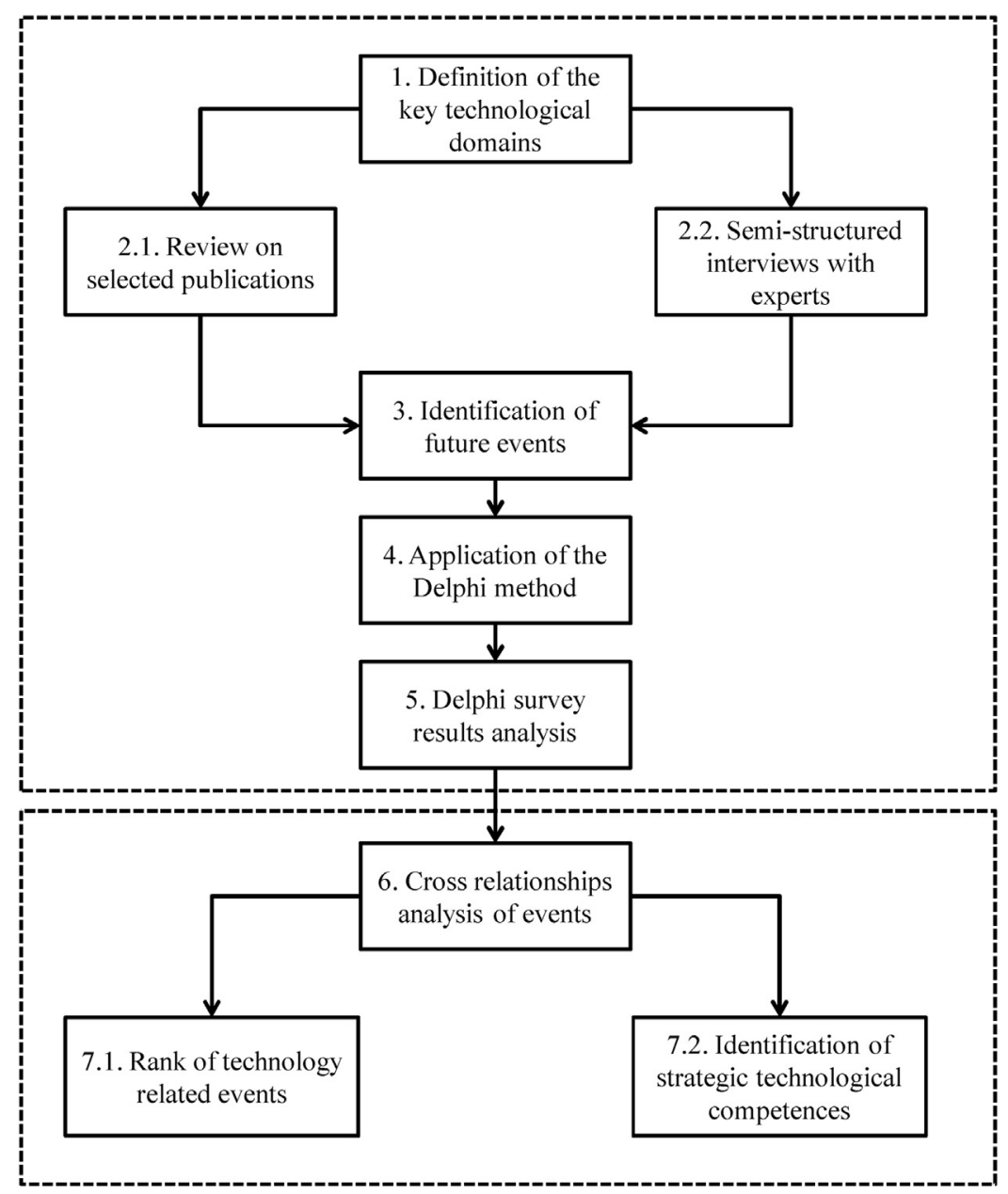

Phase 1:

Application of the

Delphi method

Fig. 1. Flowchart for the application of the extended Delphi method.

Additionally, industry publications were reviewed (Ad-hoc Industrial Advisory Group, 2010; CECIMO, 2011). These publications provide important insights about the future of manufacturing technologies (machine tools included), and trends in the regulatory environment, market and economy, both at the European and international levels.

\section{Semi-structured interviews with experts}

Invitations were sent via electronic mail to eighteen experts. The interview protocol used is divided into three parts (macroenvironment, micro-environment and technology) which are related with the three dimensions of foresight studies proposed by Vecchiato and Roveda (2010), as described in the literature review. The defined time horizon was ten years.

\section{Identification of future events}

S citation analysis of the interviews' transcripts and of the publications was performed and enabled the identification of the most frequently cited future events by the experts. Through this analysis, it was possible to identify several future events for the sheet metal processing equipment industry.

\section{Application of the Delphi method}

The identified events were used in a Delphi survey which was applied to a larger panel of experts in sheet metal industry. Special care was put to ensure that experts have the technological background in the domains that were the focus of the study.

\section{Delphi survey results analysis}

After the period designated for filling the survey, a convergence analysis of experts' evaluations was performed using appropriate metrics (median and standard deviation).

\section{Cross relationships analysis of events}

The results were used as inputs for a methodology that complements the Delphi method and enables the cross relationships 
analysis between the events. Using a metric for condensing the information provided by the experts in each event statement from the Delphi survey (the "event relevance index") and an adapted Quality Function Deployment (QFD) matrix, the rank of the most important technology related events (7.1) and strategic technological competences (7.2) could be identified. The application of this methodology is described in sub Section 4.3.

The criteria for evaluating the quality of the research design follows also Yin's approach to case study research validation: construct validity is ensured by using multiple sources of evidence (reports, interviews, documents, etc.) and by developing a sequence of evidence in which the researchers had a participant-observation role in the application of the proposed methodology. Internal validity is assured by addressing relevant literature, while external validity is achieved by empirical evidence collected from an application in a case study. Finally, reliability is achieved by following a detailed and documented research process.

\section{Methodology development, application and results analysis}

This section is divided in three parts: sub section 4.1 describes the preparation, application and survey results analysis from the Delphi method, sub section 4.2 provides details about the proposed methodology, namely on how it uses the results from the Delphi survey method to enable the cross relationships analysis between events, and section 4.3 describes the application of the proposed methodology in the company.

\subsection{Delphi method application: results analysis}

The Delphi method was applied during a period of approximately three months. As described in Fig. 1 from section 3 , the process started with interviews with experts and a review of selected publications. A total of fifteen experts were interviewed: eight of these experts came from the industry, the other seven experts have an academic background. Ten interviews were conducted face-to-face, while the remaining five were conducted via audio conference. Experts authorized the recording of the interviews, which lasted fortyfive minutes on average.

Along with the review on the publications, the transcripts from the fifteen interviews were analysed, which enabled the identification of twenty-seven future events for the sheet metal processing equipment industry, which can be seen in Table 1 . Although most of these events relate to technological developments, some also relate to possible changes in market structure, regulation and in the economy.

The survey was implemented under the principles of the Real Time Delphi survey (Gordon \& Pease, 2006), a web-based and round-less approach of the Delphi method.

The platform used was the Surveylet provided by the Calibrum Corporation (www.calibrum.com). For each event, experts were asked to answer four questions:

- What is your knowledge level in this subject? (available answers: from 1-low knowledge to 4-high knowledge)

- What is the expected impact of this event? (available answers: from 1-low impact to 4-high impact)

- When will it happen? (available answers: < 5 years, 5-10 years, 10-20 years, $>20$ years, Never)

- How likely is it to occur? (available answers: from 1-low likelihood to 4-high likelihood)

In addition to answering these questions, experts were also able to provide comments at will for each statement. Sixty-four experts were invited to fill the survey during a period of three weeks. In the end, twenty-seven experts completed the survey (a $42 \%$ response rate), providing seventy comments.

Table 1 presents the survey results. Convergence was assessed using the mean to calculate the responses' central tendency. The dispersion of responses was calculated using the standard deviation (SD).

The calculation of the mean and median time of realization for each survey statement was weighted with the average year for each option:

- $<5$ years (2012-2016): 2014

- 5-10 years (2017-2021): 2019

- 10-20 years (2022-2031): 2027

- > 20 years (2032-2041): 2036

Important to notice that, after filling the survey for the first time, the experts were able to visualize, in real time, the anonymous comments and answers from other experts, and change their original answers whenever they wanted. In this way, the Delphi method can facilitate convergence of judgements and consensus building.

\subsection{Development of the methodology}

The methodology described in this section complements the Delphi method by addressing the two previously identified shortcomings of the method in the literature review: the method's inability to consider inter-relationships and synergies between events and the lack of a mechanism or procedure to support the formulation of a technology strategy. 
Table 1

Delphi survey results analysis.

\begin{tabular}{|c|c|c|c|c|c|}
\hline \multirow[t]{2}{*}{ Event } & \multirow{2}{*}{$\begin{array}{c}\text { Knowledge level } \\
\text { Mean } \\
\text { Standard } \\
\text { deviation }\end{array}$} & \multirow{2}{*}{$\begin{array}{l}\text { Expected } \\
\text { impact } \\
\text { Mean } \\
\text { Standard } \\
\text { deviation }\end{array}$} & \multicolumn{2}{|c|}{ Time of occurrence } & \multirow{2}{*}{$\begin{array}{c}\text { Likelihood of } \\
\text { occurrence } \\
\text { Mean } \\
\text { Standard deviation }\end{array}$} \\
\hline & & & $\begin{array}{c}\text { Mean } \\
\text { Standard } \\
\text { deviation }\end{array}$ & Never(\%) & \\
\hline \multirow{2}{*}{$\begin{array}{l}\text { 1. Countries with low labor costs introduce a growing number of } \\
\text { innovations in sheet metal processing technologies. }\end{array}$} & 2,8 & 2,9 & 2018,8 & $7 \%$ & 2,5 \\
\hline & 1.8 & 1.9 & 10.7 & & 2.1 \\
\hline \multirow{2}{*}{$\begin{array}{l}\text { 2. South Korean companies introduce worldwide innovations in } \\
\text { sheet metal processing technologies. }\end{array}$} & 2,2 & 2,7 & 2016,8 & $7 \%$ & 2,6 \\
\hline & 2.1 & 1.9 & 7.9 & & 2 \\
\hline \multirow{2}{*}{$\begin{array}{l}\text { 3. Machine orders from low-labor-cost countries involve greater } \\
\text { automation. }\end{array}$} & 2,7 & 2,8 & 2019,1 & $7 \%$ & 2,6 \\
\hline & 2 & 1.6 & 12.1 & & 1.9 \\
\hline \multirow{2}{*}{$\begin{array}{l}\text { 4. Large numbers of countries base their security rules on the } \\
\text { principles set out in the European law. }\end{array}$} & 2,7 & 3,0 & 2017,9 & $0 \%$ & 2,9 \\
\hline & 2.1 & 2 & 10.7 & & 1.8 \\
\hline \multirow{2}{*}{$\begin{array}{l}\text { 5. Europe implements stricter machine tool market surveillance as } \\
\text { a consequence of more stringent environmental regulations. }\end{array}$} & 2,7 & 3,2 & 2016,8 & $3 \%$ & 3,0 \\
\hline & 1.9 & 1.5 & 7.7 & & 1.9 \\
\hline \multirow{2}{*}{$\begin{array}{l}\text { 6. Imported and low-cost machinery faces difficulties entering the } \\
\text { European market. }\end{array}$} & 2,6 & 2,7 & 2016,9 & $17 \%$ & 2,2 \\
\hline & 1.7 & 2.1 & 11.7 & & 2.4 \\
\hline \multirow{2}{*}{$\begin{array}{l}\text { 7. The concept of modularity in machine design is extended to } \\
\text { adaptive production systems. }\end{array}$} & 3,1 & 3,4 & 2017,4 & $0 \%$ & 3,4 \\
\hline & 1.6 & 1.4 & 9.3 & & 1.3 \\
\hline \multirow{2}{*}{$\begin{array}{l}\text { 8. Laser processing replaces traditional sheet metal cutting } \\
\text { processes (punching machines, shears, etc.). }\end{array}$} & 3,2 & 3,0 & 2018,8 & $7 \%$ & 3,0 \\
\hline & 1.5 & 1.5 & 11.5 & & 1.7 \\
\hline \multirow{2}{*}{$\begin{array}{l}\text { 9. The market prefers laser applications for remote processing of } \\
\text { sheet metal over more traditional processes. }\end{array}$} & 2,8 & 2,8 & 2018,0 & $7 \%$ & 2,7 \\
\hline & 1.6 & 1.7 & 9.4 & & 1.6 \\
\hline \multirow{2}{*}{$\begin{array}{l}\text { 10. The metal construction sector adopts sheet processing } \\
\text { machinery which incorporates the lean philosophy (lean } \\
\text { production). }\end{array}$} & 2,8 & 3,1 & 2015,7 & $0 \%$ & 3,3 \\
\hline & 1.8 & 1.9 & 4.9 & & 1.7 \\
\hline \multirow{2}{*}{$\begin{array}{l}\text { 11. Massive adoption of virtual imaging technology for machine } \\
\text { tooling and process control. }\end{array}$} & 2,4 & 2,8 & 2019,6 & $0 \%$ & 2,7 \\
\hline & 1.7 & 1.5 & 9.9 & & 1.8 \\
\hline \multirow{2}{*}{$\begin{array}{l}\text { 12. Massive adoption of laser forming as complementary process } \\
\text { for corrections in hard-to-form materials. }\end{array}$} & 2,5 & 2,4 & 2021,9 & $3 \%$ & 2,3 \\
\hline & 1.9 & 1.8 & 12.7 & & 1.8 \\
\hline \multirow{2}{*}{$\begin{array}{l}\text { 13. Laser processing machines with } \mathrm{CO} 2 \text { sources loses significant } \\
\text { market share. }\end{array}$} & 2,8 & 2,9 & 2017,1 & $0 \%$ & 2,7 \\
\hline & 2 & 1.8 & 8.9 & & 1.9 \\
\hline 14. Hybridization (multiple processes in a single machine) is & 2,7 & 3,0 & 2019,0 & $3 \%$ & 2,7 \\
\hline massively adopted in sheet metal processing equipment. & 1.8 & 1.5 & 10.9 & & 2 \\
\hline 15. Trend towards modular architecture in sheet metal processing & 3,0 & 3,0 & 2017,4 & $0 \%$ & 3,0 \\
\hline machinery. & 1.7 & 1.8 & 10.2 & & 2.1 \\
\hline 16. Massive adoption of tablets in sheet metal processing & 2,6 & 2,5 & 2017,2 & $7 \%$ & 2,7 \\
\hline machines. & 2.4 & 2.1 & 9.4 & & 2.2 \\
\hline 17. Polymer concrete becomes the main structural material for & 2,4 & 2,5 & 2018,3 & $17 \%$ & 2,4 \\
\hline sheet metal machine tools. & 1.9 & 2 & 10.5 & & 1.8 \\
\hline 18. Machines for sheet metal processing incorporate lighter & 2,9 & 2,8 & 2018,3 & $0 \%$ & 3,1 \\
\hline materials in moving parts. & 1.6 & 1.9 & 13.5 & & 2 \\
\hline 19. Massive adoption of sheet processed high-strength and ultra- & 2,9 & 3,1 & 2017,2 & $3 \%$ & 3,1 \\
\hline high-strength steel. & 2.1 & 1.8 & 9.4 & & 2.3 \\
\hline 20 . The sheet processing of new materials gains $10 \%$ of the market & 2,3 & 2,7 & 2019 & $3 \%$ & 2,8 \\
\hline share of steel. & 2.2 & 1.8 & 10.2 & & 1.7 \\
\hline 21. Interfaces with voice, gestures and language recognition & 2,4 & 2,6 & 2023 & $7 \%$ & 2,4 \\
\hline $\begin{array}{l}\text { technologies are applied in the sheet metal processing } \\
\text { machines. }\end{array}$ & 1.9 & 2.1 & 14 & & 2.2 \\
\hline 22. Reaction times of millisecond are achieved in the active & 2,4 & 2,8 & 2017,5 & $3 \%$ & 2,9 \\
\hline control of machines. & 1.7 & 1.9 & 11 & & 1.8 \\
\hline 23. Massive adoption of active monitoring technologies and & 2,6 & 3,2 & 2018,8 & $3 \%$ & 2,8 \\
\hline intelligent machines with self-learning capabilities. & 1.9 & 1.4 & 11.6 & & 1.9 \\
\hline 24. Massive adoption of remote monitoring of sheet metal & 3,0 & 3,2 & 2017 & $0 \%$ & 3,2 \\
\hline machine tools. & 1.8 & 1.8 & 12.6 & & 2 \\
\hline 25. Forming forces in hybrid engines (servo motors and hydraulic & 2,6 & 2,8 & 2020,8 & $7 \%$ & 2,7 \\
\hline $\begin{array}{l}\text { systems) exceed the forces of large hydraulic machines of } \\
\text { today. }\end{array}$ & 2.1 & 2.2 & 16.2 & & 2.3 \\
\hline 26. Unit cost per linear measurement (meters, centimeters, etc.) is & 2,4 & 2,7 & 2018,8 & $0 \%$ & 2,5 \\
\hline half of the present-day cost in sheet metal cutting processes. & 2 & 1.9 & 10.3 & & 1.8 \\
\hline 27. Unit cost per linear measurement (meters, centimeters, etc.) is & 2,3 & 2,1 & 2019,9 & $0 \%$ & 2,4 \\
\hline half of the present-day cost in sheet bending processes. & 1.9 & 1.4 & 13 & & 1.7 \\
\hline
\end{tabular}

\subsubsection{Condensation of information provided by experts}

Typically, in a Delphi survey, a panel of experts provide their best guesses about the impact, the time and likelihood of occurrence for each events portrayed in the survey. Although these are regarded as relevant information for strategic purposes, these indicators still provide little clarity about the priorities of the organization in relation to future events, or on how each indicator (impact, probability and time of occurrence) influences the decision-making process inside the organization. 
In this paper, we propose the use of a single metric that is capable of condensing the information contained in the experts' responses and reflect different degrees of events' relevance. As can be observed in Table 1, the events are evaluated according to their impact, likelihood and time of occurrence. These three indicators are used to provide a single metric that represents the relevance of an event for the organization.

Once, and as expected, experts have divergent opinions over the portrayed topics, the proposed metric should also consider the dispersion of the judgments. This issue is addressed by using the coefficient of variation as a proxy for estimating the relevance of each indicator of each event. The coefficient of variation is calculated by dividing the mean by the standard deviation (SD). In fact, experts' assessments with a higher mean may indicate that an event will have a higher impact and/or likelihood of occurrence. A lower standard deviation indicates that experts agreed more with respect to the assessment of the event or the uncertainty about an event is lower. As such, assessments with lower mean and higher standard deviation are then penalized in terms of relevance.

In order to integrate these three indicators into a single metric, one needs to convert the interval years available for experts into corresponding Likert scales. Hereinafter, time of occurrence indicator is converted into the urgency indicator, which represents how close to the present time the realization of an event is. Therefore, interval years which are more distant in time will have corresponding lower Likert scales, while the ones close in time will have greater corresponding Likert scales, as described below:

- < 5 years (2012-2016): 4

- 5-10 years (2017-2021): 3

- 10-20 years (2022-2031): 2

- After 20 years: 1

Different weights $\left(\mathrm{w}_{\mathrm{i}}\right)$ can be used for each indicator to reproduce varying degrees of importance to the organization. Thus, the event relevance index (ERI) can be described by Eq. (1).

$$
\text { Event relevance index }=\frac{\left[w_{1} \cdot\left(\frac{\text { Mean }_{(\text {impact })}}{S D_{(\text {impact })}}\right)+w_{2} \cdot\left(\frac{\text { Mean }_{(\text {likelihood })}}{S D_{(\text {likelihood })}}\right)+w_{3} \cdot\left(\frac{\text { Mean }_{(\text {urgency) }}}{S D_{(\text {urgency })}}\right)\right]}{\left(w_{1}+w_{2}+w_{3}\right)}
$$

\subsubsection{Cross-events analysis}

In management literature, cross relationships analyses have been relying on matrix-type of tools. These matrices have been employed by consultants and managers in business, as well as by academics, for its simplicity in communication, flexibility and easiness to integrate, thus satisfying the generic requirements of an adequate tool for technology management (Phaal et al., 2006).

Among such tools, QFD is a matrix type of tool used for translating customers' requirements into technical and engineering characteristics, which has also been applied in foresight studies (Lee, Phaal, \& Lee, 2013). Due to its wide acceptance, an adapted version of the QFD matrix is used to analyse the relationships between the events from the Delphi survey.

Observing the Delphi survey, the events indicate different types of predictions. For example, events 1 and 2 (see Table 1 ) indicate future changes in competition. Event 3 is related with market dynamics, but more specifically with emerging customers' needs. Events 4, 5 and 6 deal with likely changes in regulations. The remaining events are associated with technologies. Therefore, it is possible to divide the events of the Delphi survey in two sets: technology related and non-technology related events.

Non-technology related events represent external conditions and drivers which may influence the technologies' diffusion process. The relationships between these two sets of events should be analysed in order to point out the most promising technologies. Following the principles of cross-relationships analysis explained above, the synergetic effect between non-technology related events and technology related events can be evaluated via a matrix tool.

By building an adapted QFD matrix, such as the one portrayed in Fig. 2, decision makers are able to analyse the relationships between different events. Each calculated ERIs for each event is then normalized for the two groups of events, i.e., the technology related and non-technology related events. Then, the normalized ERIs are placed in the first row (for the technology related events) and first column (for the non-technology related events). These represent the grey cells seen Fig. 2.

The relationships between these two groups of events are assessed quantitatively using a pre-defined scale (strong, moderate and weak relationship), like in a QFD matrix. The strength of each relationship is inserted in the intersecting cells, for each pair of technology and non-technology related events. The strength of each relationship is then multiplied by the normalized ERIs of the respective technology and non-technology related events. The absolute score of each technology is the result of the sum of all scores per technology related event, in each column of the matrix. The rank identifies the most important technologies.

Finally, the organizational difficulty is an indicator used to measure how difficult it would be for the organization to develop internally the technology mentioned in each Delphi survey event. The organizational difficulty indicator is based on a 5 point Likert scale, on an ascending order of difficulty (1-very easy to 5-very difficult). Its assessment should be performed by managers directly involved in technology development inside the organization, who have a more comprehensive knowledge about internal technological capabilities and competences.

Observing the proposed methodology, one may argue that the events relationships are already taken into account in the judgments of the experts. For example, when an expert states that an event describing more rigid environmental regulations is highly likely in the future, he/she should also assert that events describing greater diffusion of environmentally friendly technologies will also have a high probability of occurrence in the future. The Delphi method, with its constituting features, does not incorporate any mechanism that can overcome 


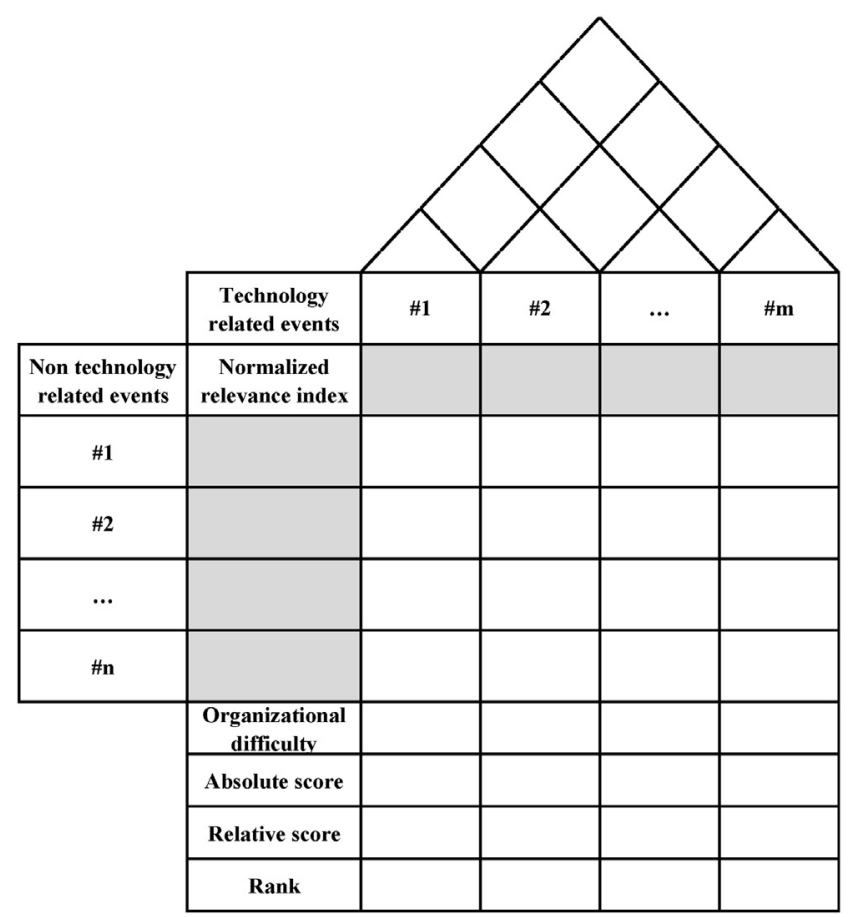

Legend:
\begin{tabular}{|cc|}
\hline++ & Strong correlation \\
+ & Correlation \\
O & Strong relationship \\
$\square$ & Moderate relationship \\
$\Delta$ & Weak relationship \\
\hline
\end{tabular}

Fig. 2. Adapted QFD matrix for events relationship analysis.

logical inconsistencies in the experts' assessments. By applying the cross-events assessments through the modified QFD matrix, any existing logical inconsistency can be minimized or corrected in order to provide a more reliable indicator about the importance of each event.

\subsubsection{Identification of strategic technological competences}

The selection of technologies and required technological competences and capabilities are among the decisions of technology strategy programs (Burgelman et al., 2001). The first decision has a direct answer from application of the methodology in the Delphi survey results: the ERI for each technology related event reveals the most relevant technologies for the future.

The decision concerning the required technological competences and capabilities requires an additional analysis. Technology competences are represented by knowledge and skills embedded in technologies (Marino, 1996), and each technology may embody one or multiple competences and capabilities. As seen in Table 1, technology related event 7 reflects competences in machine design, mechatronics and process automation and integration. Event 11 reflects competences in ICT, industrial electronics and, as with event 7, also embodies competences in mechatronics.

Since technological related events may embody one or more technical knowledge areas or competences, these competences need to be identified and their link with the respective technology related event(s) made clear. Fig. 3 shows a schematic representation of these relationships.

In order to make these linkages explicit, each technological related event is linked with one or more technology competence, namely the ones identified previously: Information and Communication Technologies (ICT), Materials, Robotics, Automation, Optics and Photonics, Sensing, Mechatronics, Machine Design and Industrial Electronics. These linkages can be performed in the "roof" of the modified QFD matrix: a strong correlation $(++)$ or moderate correlation $(+)$ between technology related events that embody the

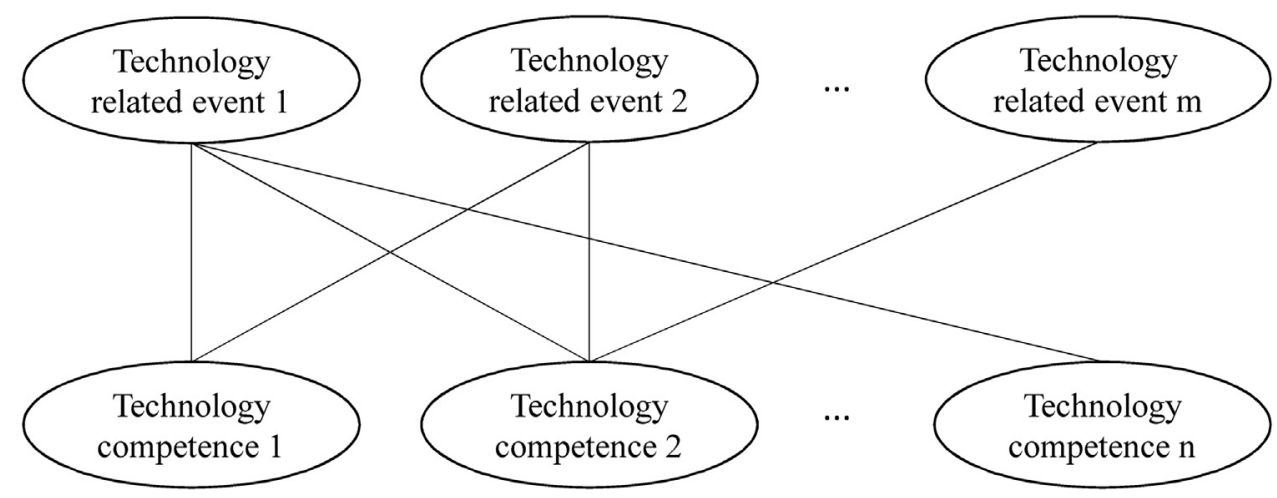

Fig. 3. Relationships between technology events and competences. 
same competences is placed in the intersecting cells of the roof.

Since each technological competence may be related to one or more technology related events, a score for each technological competence is calculated by summing the absolute scores from all the linked technology related events, and a ranking of the most important technological competences can be achieved. This procedure provides basis for answering the question concerning which are the required technological competences, by indicating the most important technological competences for the future.

A more robust analysis from the results of the Delphi is expected by applying the proposed methodology. The ERI provides a multidimensional perspective about the diffusion process of technologies, since it condenses the evaluations provided by the experts for three indicators per event. Additionally, the ERI reflects the importance of each indicator in the organization's decision-making process by attributing different weights. The cross-events relationship analysis through the modified QFD matrix minimizes possible logical inconsistencies from the Delphi survey. In this way, the analytical structure and the supporting calculations of the methodology provide basis for obtaining a ranking of the most important technologies and competences that reflects the synergetic effect between future events and the decision making process inside the organization, which would not be possible only through the results of the Delphi survey.

Finally, it is important to note that the proposed methodology differs from the Cross-Impact Method developed by Gordon (1994) since it incorporates a holistic perspective about the relevance of an event. Moreover, the proposed methodology is linked with the technology strategy formulation process.

\subsection{Application of the methodology}

The proposed methodology was applied using the Delphi survey results described in sub section 4.1 as inputs. Through meetings with industrial partner's management and engineers that supported the realization of this study, information was collected about the applications and the potential of the technologies depicted in the survey, which in turn enabled the events relationships assessments.

Events 26 and 27 were excluded from the analysis since they do not portray any specific technology development but improvements in specific technical attributes in machines. Data collected from the survey was then used to calculate the ERI for each event, and then normalized for each of the two groups of events. Same weights were attributed for each indicator (impact, likelihood

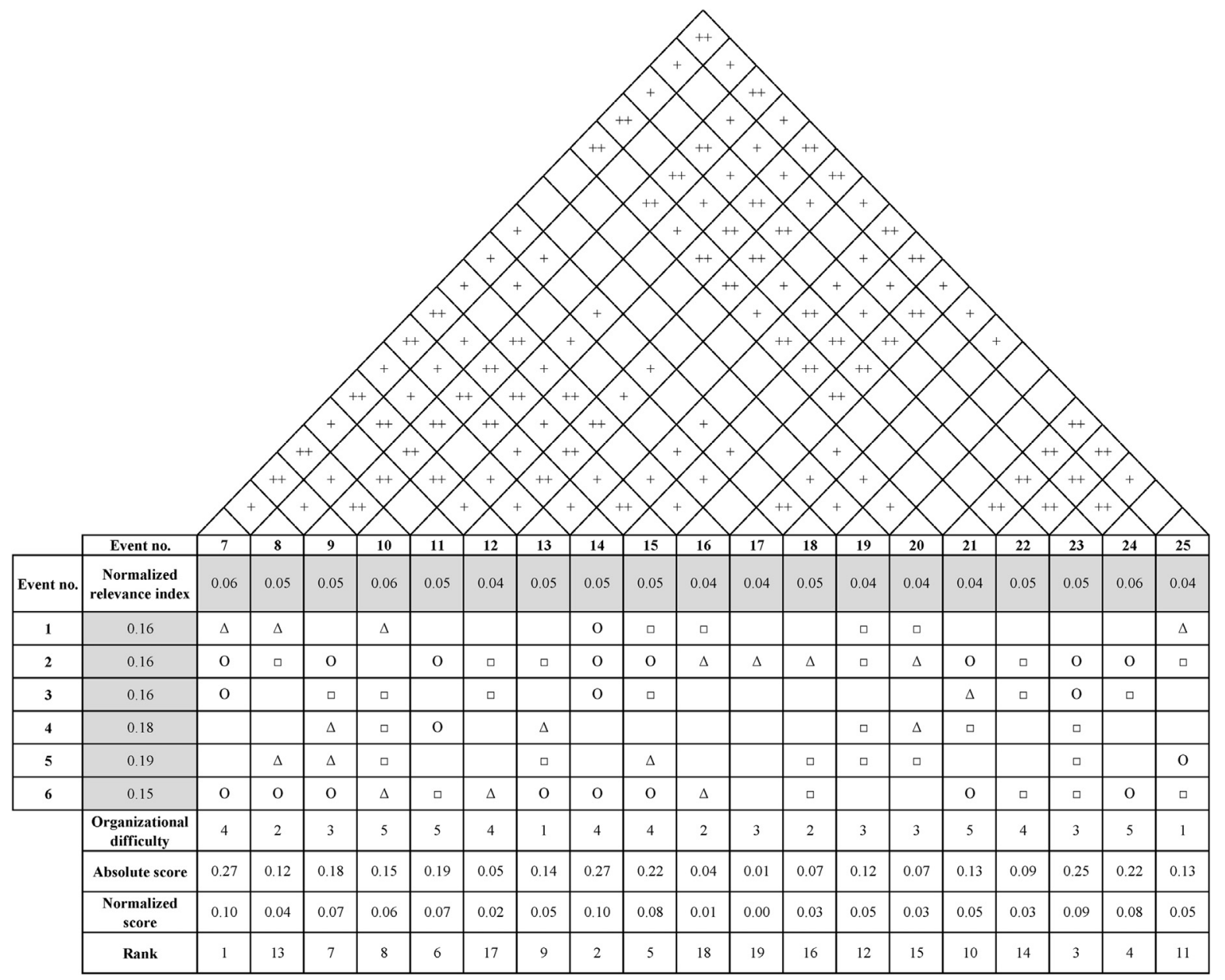

Fig. 4. Cross-events relationship analysis. 
Table 2

Rank of technological competences.

\begin{tabular}{|c|c|c|c|c|c|c|c|c|c|}
\hline \multicolumn{10}{|c|}{ Technological competences } \\
\hline Event no. & $\begin{array}{l}\text { Machine } \\
\text { design }\end{array}$ & Sensing & Robotics & Mechatronics & $\begin{array}{l}\text { Process automation and } \\
\text { integration }\end{array}$ & ICT & Materials & $\begin{array}{l}\text { Optics and } \\
\text { Photonics }\end{array}$ & $\begin{array}{l}\text { Industrial } \\
\text { Electronics }\end{array}$ \\
\hline 7 & $\mathrm{x}$ & & & $\mathrm{x}$ & $\mathrm{X}$ & & & & \\
\hline 8 & $\mathrm{x}$ & & & & & & & $\mathrm{x}$ & \\
\hline 9 & & $\mathrm{X}$ & $\mathrm{x}$ & $\mathrm{x}$ & $\mathrm{x}$ & & & $\mathrm{x}$ & $\mathrm{X}$ \\
\hline 10 & $\mathrm{x}$ & & $\mathrm{X}$ & & $\mathrm{x}$ & & & & \\
\hline 11 & & & & $\mathrm{X}$ & & $\mathrm{X}$ & & & $\mathrm{X}$ \\
\hline 12 & $\mathrm{x}$ & $\mathrm{X}$ & & & $\mathrm{x}$ & & & $\mathrm{x}$ & $\mathrm{x}$ \\
\hline 13 & & & & $\mathrm{x}$ & & & & $\mathrm{X}$ & \\
\hline 14 & $\mathrm{x}$ & & & $\mathrm{x}$ & $\mathrm{x}$ & & & & \\
\hline 15 & $\mathrm{x}$ & & & $\mathrm{x}$ & $\mathrm{x}$ & & & & \\
\hline 16 & & & & & $\mathrm{x}$ & $\mathrm{x}$ & & & $\mathrm{x}$ \\
\hline 17 & $\mathrm{x}$ & & & & & & $\mathrm{X}$ & & \\
\hline 18 & $\mathrm{x}$ & & & & & & $\mathrm{x}$ & & \\
\hline 19 & & & & & & & $\mathrm{X}$ & & \\
\hline 20 & & & & & & & $\mathrm{X}$ & & \\
\hline 21 & & $\mathrm{X}$ & & $\mathrm{x}$ & $\mathrm{x}$ & $\mathrm{x}$ & & & $\mathrm{x}$ \\
\hline 22 & & $\mathrm{X}$ & & $\mathrm{x}$ & $\mathrm{x}$ & $\mathrm{x}$ & & & $\mathrm{x}$ \\
\hline 23 & & $\mathrm{X}$ & & & $\mathrm{x}$ & $\mathrm{X}$ & & & $\mathrm{x}$ \\
\hline 24 & & & & & $\mathrm{x}$ & $\mathrm{x}$ & & & \\
\hline 25 & $\mathrm{x}$ & & & $\mathrm{x}$ & & & & & $\mathrm{x}$ \\
\hline Total score & 1.3 & 0.6 & 0.3 & 1.2 & 1.6 & 0.7 & 0.5 & 0.5 & 0.7 \\
\hline $\begin{array}{l}\text { Relative } \\
\text { score }\end{array}$ & 0.18 & 0.08 & 0.04 & 0.16 & 0.22 & 0.09 & 0.07 & 0.07 & 0.10 \\
\hline Rank & 2 & 6 & 9 & 3 & 1 & 5 & 8 & 7 & 4 \\
\hline
\end{tabular}

of occurrence and urgency) in the calculation of the ERIs. The cross-events relationships assessments between these two groups of events were performed using the legend from Fig. 3: a score of 9 points for a strong relationship, 4 points for moderate, 1 point for poor relationship and 0 point for no relationship. The absolute score for each technology related event is calculated by multiplying the normalized ERI of the technology related event, the normalized ERI of non-technology related events and the cross-events assessments (in the intersecting cells). Finally, for each technology related event, the results are summed and a rank of the most important technology related events was obtained, as shown in Fig. 4. According to this rank, the top 3 technology related events are events 7, 14 and 23 (refer to Table 1).

For the sole purpose of illustration, the justifications and explanations behind a number of events relationships analyses are described below.

Event 14 (see Table 1) is strongly favoured by events 3 and 6. It is expected that with a demand increase for automation from countries with lower labour costs, the market for machines capable of performing multiple manufacturing processes (reducing the need for operators) is expected to increase. Moreover, from the perspective of a company having Europe as one of its main markets (as is the case of the company), greater restrictions on the entry of low-cost competitors in this market strongly favours the market for hybrid machines incorporating more traditional sheet forming processes.

Event 23 is strongly favoured by event 3, because higher automation is expected to increase the demand for machines with active monitoring and capacity for self-learning processing. The technology portrayed in event 5 is only moderately favoured because its ability to substantially reduce process waste still needs to be demonstrated.

The "roof" in the adapted QFD matrix portrays the degree to which each technology related event is linked with the other events in terms of common technological competences. As mentioned earlier, there are nine technological competences regarded as strategic for the sheet metal processing equipment industry. In this particular study, pairs of events that have two or more technological competences in common are strongly correlated $(++)$, one is correlated $(+)$ and none is blank.

Summing the absolute scores of each event related to a technological competence provides a final score, which then reflects its strategic importance, as shown in Table 2. The top 3 strategic technological competences are "Process Automation and Integration", "Machine Design" and "Mechatronics".

The application of the methodology contributed to the generation of debate within the organization about the future directions of the sheet metal processing equipment industry. This debate involved not only technical personnel but also employees from other departments, such as marketing and sales, manufacturing, etc. The dialogue between multiple departments, promoted by the application of the methodology, helped to converge multiple perspectives towards a future oriented critical thinking inside the organization.

\section{Conclusions}

The field of technology foresight, either through standalone methods or combined methodologies, is continuously leading to new methodological developments, given its strategic importance for both private and public sectors. 
The results of a Delphi survey need to be complemented with deeper analyses to improve the preparation of R \& D projects plans. However, in situations when complementary studies cannot be afforded, organizations still need structured and practical tools to enable them to make strategic decisions. In line with the emerging foresight paradigm, a methodology combining the Delphi method and QFD is proposed in this study.

The assessment of the influence that non-technology related events may have on the diffusion of technologies is subjected to ambiguous interpretations resulting from subjective judgments. A transversal understanding is thus necessary inside organizations with respect to the relationships between external factors and technologies.

This study presents a single application of the methodology, which is a limitation for generalizability of the findings. Being a methodology that is based on existing tools (the Delphi method and QFD) that have been applied in other foresight studies at various levels (national, regional, etc.), it can be argued that the methodology could potentially also be applied in other industrial sectors. The inherent characteristics of the methodology make it of potential usefulness to industrial sectors where technology development is particularly sensitive to external drivers.

An alternative approach for the methodology could integrate the cross-events relationships analysis directly on the Delphi survey and thus benefit from a wider pool of knowledge. For example, after providing their best guesses concerning the impact, likelihood of occurrence and time of realization, experts could also provide, possibly in a second round of a typical Delphi survey, their assessment on the cross-relationships between events.

The holistic view concerning the dynamics of technology evolution in industry can contribute to an intense debate inside organizations. Participants generally come from different departments, and often have conflicting points of view. As such, the methodology can contribute to the homogenization of perspectives inside organization concerning the influence of external drivers in technological diffusion.

The proposed methodology can serve as an analytical platform to be used by organizations in supporting investment decisions in technological competences, which is a critical decision in the formulation of a technology strategy. Conceptually, this study makes a contribution towards the linkage between technology foresight and technology strategy. Further developments are expected resulting from the methodology's application in other case studies.

\section{Acknowledgements}

This research is supported by Fundação para a Ciência e a Tecnologia (scholarship reference SFRH/BD/33727/2009), within the framework of the EDAM MIT Portugal Program.

\section{Appendix A}

Actors Non technological drivers

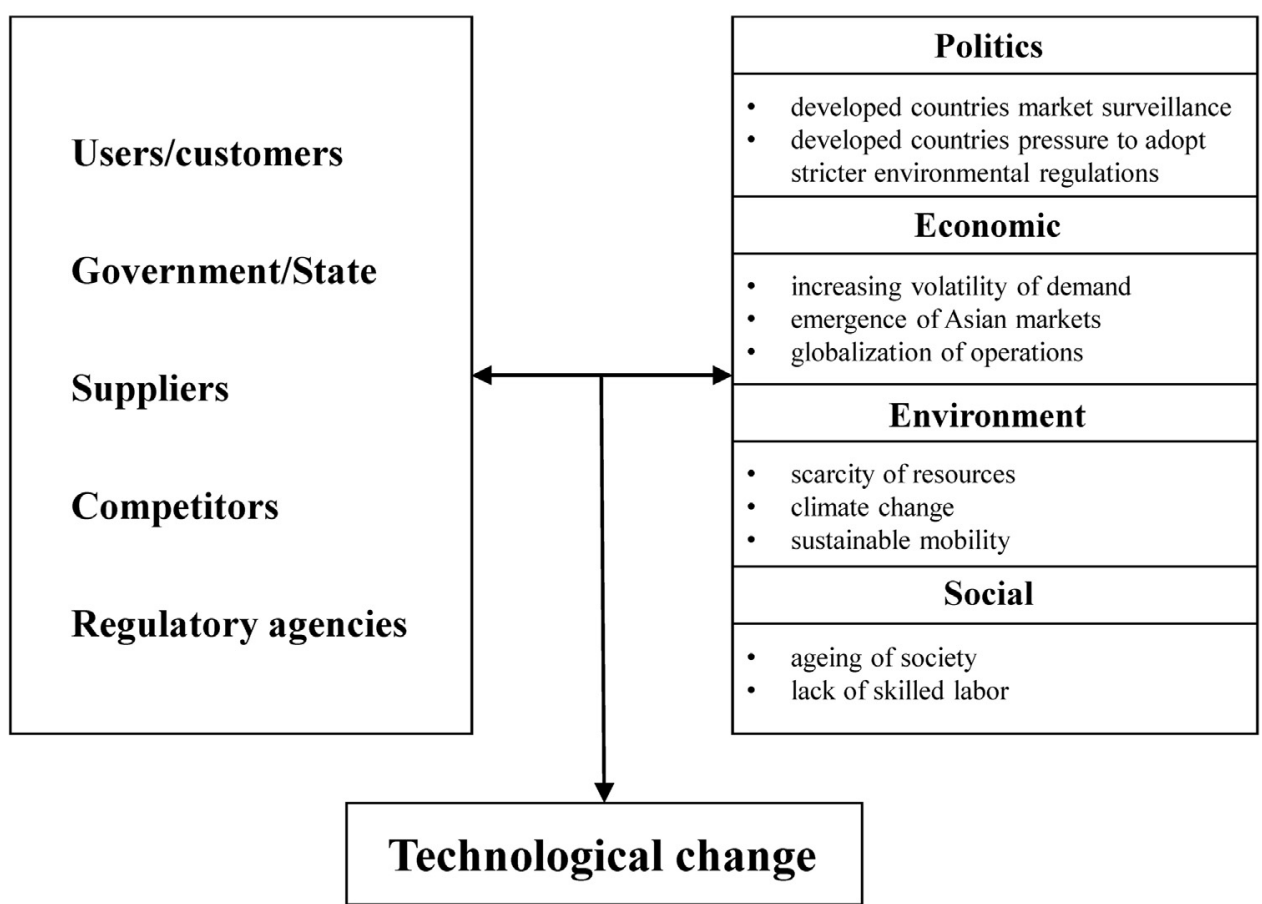

Fig. A1. Actors and drivers that influence technological change in the machine tool industry. 


\section{References}

Ad-hoc Industrial Advisory Group, Factories of the future strategic multi-annual roadmap - Strategic Multi-Annual Roadmap, European Factories of the Future Research Association, Brussels (2010). https://ec.europa.eu/research/industrial_technologies/pdf/ppp-factories-of-the-future-strategic-multiannual-roadmapinfo-day_en.pdf. (Accessed 23 October 2014).

Anderson, T. R., Daim, T. U., \& Kim, J. (2008). Technology forecasting for wireless communication. Technovation, 28(9), 602-614.

Ariss, S. S., Raghunathan, T. S., \& Kunnathar, A. (2000). Factors affecting the adoption of advanced manufacturing technology in small firms. Society for Advancement of Management - Advanced Management Journal, 65(2), 14-29.

Arnold, H. M. (2001). The recent history of the machine tool industry and the effects of technological change. Munich: University of Munich, Institute for Innovation Research and Technology Management http://www.en.inno-tec.bwl.uni-muenchen.de/research/proj/abgeschlossen/techschocks/heinrich1.pdf. (Accessed 14 October 2013).

Bañuls, V. A., \& Turoff, M. (2011). Scenario construction via Delphi and cross-impact analysis. Technological Forecasting and Social Change, 78(9), 1579-1602.

Burgelman, R. A., Christensen, C. M., \& Wheelwright, S. C. (2001). Strategic management of technology and innovation (3rd ed.). Boston: McGraw Hill/Irwin.

CECIMO - European Association of the Machine Tool Industries: Study on the competitiveness of the European machine tool industry. (2011). http://www.cecimo.eu/ site/fileadmin/Publications/Studies_and_Reports/Study_on_Competitiveness_of_the_European_Machine_Tool_Industry_-_December_2011.pdf. (Accessed 23 October 2013).

CECIMO - European Association of the Machine Tool Industries: Market Surveillance: An Industrial Policy Priority, at last! (2012). http://www.cecimo.eu/site/ publications/news/?tx_ttnews\%5Btt_news\%5D = 8\&cHash=5429a423a1ab6bd466ba96e13bc3edca. (Accessed 23 October 2013).

CECIMO - European Association of the Machine Tool Industries: Blue Competence Machine Tools (2013). http://www.cecimo.eu/site/blue-competence-mt/bluecompetence-mt/. (Accessed 17 October 2014).

Carlson, L. W. (2004). Using technology foresight to create business value. Research Technology Management, 47(5), 51-60.

Carlsson, B., \& Jacobsson, S. (1994). Technological systems and economic policy: The diffusion of factory automation in Sweden. Research Policy, 23(3), 235-248.

Chakravarti, A. K., Vasanta, B., Krishnan, A. S. A., \& Dubash, R. K. (1998). Modified Delphi methodology for technology forecasting case study of electronics and information technology in India. Technological Forecasting and Social Change, 58(1), 155-165.

Chan, L., \& Daim, T. (2012). Exploring the impact of technology foresight studies on innovation: Case of BRIC countries. Futures, 44(6), 618-630.

Chang, P. C., Wang, C. P., Yuan, B. J., \& Chuang, K. T. (2002). Forecast of development trends in Taiwan's machinery industry. Technological Forecasting and Social Change, 69(8), 781-802.

Chiesa, V. (2001). R\&D strategy and organization: Managing technical change in dynamic environments, Vol. 5. London: Imperial College Press.

Coates, V., Farooque, M., Klavans, R., Lapid, K., Linstone, H., Pistorius, C., et al. (2001). On the future of technological forecasting. Technological Forecasting and Social Change, 67(1), 1-17.

Commission, European: Eco-design of Energy-Related Products. (2009). http://ec.europa.eu/energy/efficiency/ecodesign/eco_design_en.htm. (Accessed 14 October 2013).

Commission, European: Key Enabling Technologies - A bridge to growth and jobs. (2012). http://europa.eu/rapid/press-release_MEMO-12-484_en.htm. (Accessed 14 October 2012).

Czaplicka-Kolarz, K., Stańczyk, K., \& Kapusta, K. (2009). Technology foresight for a vision of energy sector development in Poland till 2030. Delphi survey as an element of technology foresighting. Technological Forecasting and Social Change, 76(3), 327-338.

Dufva, M., \& Ahlqvist, T. (2015). Elements in the construction of future-orientation: A systems view of foresight. Futures, 73, $112-125$.

Eto, H. (2003). The suitability of technology forecasting/foresight methods for decision systems and strategy: A Japanese view. Technological Forecasting and Social Change, $70(3), 231-249$.

Gardner, R. (2014). The World machine-tool output \& consumption survey. Gardner Research, Cincinnati. http://www.gardnerweb.com/cdn/cms/2014wmtocs SURVEY.pdf. (Accessed 17 November 2014).

The handbook of technology foresight: Concepts and practice. In L. Georghiou, J. C. Harper, M. Keenan, I. Miles, \& R. Popper (Eds.), Cheltenham: Edward Elgar Publishing.

Gordon, T., \& Pease, A. (2006). RT Delphi: An efficient, round-less almost real time Delphi method. Technological Forecasting and Social Change, 73(4), 321-333.

Gordon, T. (1994). Cross-Impact Method. United Nations University Millennium Project. http://www1.ximb.ac.in/users/fac/dpdash/dpdash.nsf/ 23e5e39594c064ee852564ae004fa010/2a7a6240bcf05ebde5256906000a7322/\$FILE/Cross-im.pdf. (Accessed 17 October 2014).

Gupta, U. G., \& Clarke, R. E. (1996). Theory and applications of the Delphi technique: A bibliography (1975-1994). Technological Forecasting and Social Change, 53(2), $185-211$

Haegeman, K., Marinelli, E., Scapolo, F., Ricci, A., \& Sokolov, A. (2013). Quantitative and qualitative approaches in Future-oriented Technology Analysis (FTA): From combination to integration? Technological Forecasting and Social Change, 80(3), 386-397.

Heger, T., \& Rohrbeck, R. (2012). Strategic foresight for collaborative exploration of new business fields. Technological Forecasting and Social Change, 79(5), 819-831.

Heiko, A., Vennemann, C. R., \& Darkow, I. L. (2010). Corporate foresight and innovation management: A portfolio-approach in evaluating organizational development. Futures, 42(4), 380-393.

Heiko, A., Bañuls, V. A., Turoff, M., Skulimowski, A. M., \& Gordon, T. J. (2015). Foresight support systems: The future role of ICT for foresight. Technological Forecasting and Social Change, 97, 1-6.

Hines, A., \& Gold, J. (2015). An organizational futurist role for integrating foresight into corporations. Technological Forecasting and Social Change, 101, 99-111.

Johnston, R. (2001). Foresight - Refining the process. International Journal of Technology Management, 21(7-8), 711-725.

Kameoka, A., Yokoo, Y., \& Kuwahara, T. (2004). A challenge of integrating technology foresight and assessment in industrial strategy development and policymaking. Technological Forecasting and Social Change, 71(6), 579-598.

Kathuria, V. (1999). Role of externalities in inducing technical change: A case study of the indian machine tool industry. Technological Forecasting and Social Change, 61(1), 25-44.

Kayser, V., \& Bierwisch, A. (2015). Using twitter for foresight: An opportunity? Futures, 84(Part A), 50-63.

Keller, J., \& Heiko, A. (2014). The influence of information and communication technology (ICT) on future foresight processes-Results from a Delphi survey. Technological Forecasting and Social Change, 85, 81-92.

Kong, R. L. (1996). The role of user firms in the innovation of machine tools: The Japanese case'. Research Policy, 25(4), 491-507.

Lee, J. H., Phaal, R., \& Lee, S. H. (2013). An integrated service-device-technology roadmap for smart city development. Technological Forecasting and Social Change, $80(2), 286-306$.

Linstone, H. A., \& Turoff, M. (2002). The Delphi method: Techniques and applications. New Jersey: Addison-Wesley.

Linstone, H. A., \& Turoff, M. (2011). Delphi: A brief look backward and forward. Technological Forecasting and Social Change, 78(9), 1712-1719.

Linton, J. D. (2002). Implementation research: State of the art and future directions. Technovation, 22(2), 65-79.

Maio Mackay, M., \& Metcalfe, M. (2002). Multiple method forecasts for discontinuous innovations. Technological Forecasting and Social Change, 69(3), 221-232.

Marino, K. (1996). Developing consensus on firm competencies and capabilities. The Academy of Management Executive, 10(3), 40-51.

Meesapawong, P., Rezgui, Y., \& Li, H. (2014). Planning innovation orientation in public research and development organizations: Using a combined Delphi and analytic hierarchy process approach. Technological Forecasting and Social Change, 87, 245-256.

Meissner, D. (2012). Results and impact of national foresight-studies. Futures, 44(10), 905-913.

Miemis, V., Smart, J., \& Brigis, A. (2012). Open foresight. Journal of Future Studies, 17(1), 91-98.

Miles, I. (2010). The development of technology foresight: A review. Technological Forecasting and Social Change, 77(9), 1448-1456.

Mishra, S., Deshmukh, S. G., \& Vrat, P. (2002). Matching of technological forecasting technique to a technology. Technological Forecasting and Social Change, 69(1), $1-27$. 
Nowack, M., Endrikat, J., \& Guenther, E. (2011). Review of Delphi-based scenario studies: Quality and design considerations. Technological Forecasting and Social Change, 78(9), 1603-1615.

Phaal, R., Farrukh, C. J. P., \& Probert, D. R. (2004). Technology roadmapping - A planning framework for evolution and revolution. Technological Forecasting and Social Change, 71(1-2), 5-26.

Phaal, R., Farrukh, C. J. P., \& Probert, D. R. (2006). Technology management tools: Concept, development and application. Technovation, 26(3), 336-344.

Pietrobelli, C., \& Puppato, F. (2016). Technology foresight and industrial strategy. Technological Forecasting and Social Change, 110, $117-125$.

Porter, A. L. (2010). 'Technology foresight: Types and methods. International Journal of Foresight and Innovation Policy, 6(1-3), 36-45.

Prokesch, T., von der Gracht, H. A., \& Wohlenberg, H. (2015). Integrating prediction market and Delphi methodology into a foresight support system—-Insights from an online game. Technological Forecasting and Social Change, 97, 47-64.

Raford, N. (2015). Online foresight platforms: Evidence for their impact on scenario planning \& strategic foresight. Technological Forecasting and Social Change, 97 , $65-76$.

Reger, G. (2001). Technology foresight in companies: From an indicator to a network and process perspective. Technology Analysis \& Strategic Management, 13(4), 533-553.

Rohrbeck, R., \& Gemünden, H. G. (2011). Corporate foresight: Its three roles in enhancing the innovation capacity of a firm. Technological Forecasting and Social Change, $78(2), 231-243$.

Rohrbeck, R., \& Schwarz, J. O. (2013). The value contribution of strategic foresight: Insights from an empirical study of large European companies. Technological Forecasting and Social Change, 80(8), 1593-1606.

Rohrbeck, R., Arnold, H. M., \& Heuer, J. (2007). Strategic Foresight in multinational enterprises - A case study on the Deutsche Telekom laboratories'. ISPIM-Asia 2007 conference (pp. 1-12).

Rohrbeck, R., Thom, N., \& Arnold, H. (2015). IT tools for foresight: The integrated insight and response system of Deutsche Telekom innovation laboratories. Technological Forecasting and Social Change, 97, 115-126.

Rohrbeck, R. (2012). Exploring value creation from corporate-foresight activities. Futures, 44(5), 440-452.

Rowe, G., \& Wright, G. (2011). The Delphi technique: Past, present, and future prospects-Introduction to the special issue. Technological Forecasting and Social Change, 78(9), 1487-1490.

Rowe, G., Wright, G., \& Bolger, F. (1991). Delphi: A reevaluation of research and theory. Technological Forecasting and Social Change, 39(3), $235-251$.

Ruff, F. (2015). The advanced role of corporate foresight in innovation and strategic management-Reflections on practical experiences from the automotive industry. Technological Forecasting and Social Change, 101, 37-48.

Santos (2014). Development of an integrated framework for the definition of technology strategies. PhD thesis. University of Minho: Department of Production and Systems.

Shin, T. (1998). Using Delphi for a long-range technology forecasting, and assessing directions of future R \& D activities the Korean exercise. Technological Forecasting and Social Change, 58(1), 125-154.

Stelzer, B., Meyer-Brötz, F., Schiebel, E., \& Brecht, L. (2015). Combining the scenario technique with bibliometrics for technology foresight: The case of personalized medicine. Technological Forecasting and Social Change, 98, 137-156.

Streppel, A. H., Klingenberg, W., \& Singh, U. P. (2008). Advances in sheet metal forming applications. International Journal of Machine Tools and Manufacture, 48(5), 483-484.

Tseng, F.-M., Cheng, A.-C., \& Peng, Y.-N. (2009). Assessing market penetration combining scenario analysis, Delphi, and the technological substitution model: The case of the OLED TV market. Technological Forecasting and Social Change, 76(7), 897-909.

Vecchiato, R., \& Roveda, C. (2010). Strategic foresight in corporate organizations: Handling the effect and response uncertainty of technology and social drivers of change. Technological Forecasting and Social Change, 77(9), 1527-1539.

Vecchiato, R. (2015). Creating value through foresight: First mover advantages and strategic agility. Technological Forecasting and Social Change, 101, 25-36.

Wang, M. Y., \& Lan, W. T. (2007). Combined forecast process: Combining scenario analysis with the technological substitution model. Technological Forecasting and Social Change, 74(3), 357-378.

Wonglimpiyarat, J. (2007). National foresight in science and technology strategy development. Futures, 39(6), 718-728.

Yin, R. K. (2009). Case study research: Design and methods. London, United Kingdom: Sage publications.

de Figueiredo Porto, C. A., Marques, E., \& Santos, A. B. A. (2010). Prospective in Brazil: The power to build the future. Technological Forecasting and Social Change, 77(9), 1550-1558.

van Meulen, B., \& der Lohnberg, A. (2001). The use of foresight: Institutional constraints and conditions. International Journal of Technology Management, 21(7-8), $680-693$. 